\title{
ANÁLISE DO PROGRAMA DE INCLUSÃO DIGITAL NAVEGAPARÁ EM ESCOLAS DA REDE ESTADUAL DO MUNICÍPIO DE BELÉM
}

\author{
Waléria de Melo Magalhães - FAPAN \\ waleria.magalhaes@gmail.com \\ Benedito J. Pinheiro Ferreira - UFPA \\ ferreira@ufpa.br \\ Marianne Kogut Eliasquevici - UFPA \\ mariane@ufpa.br
}

\begin{abstract}
Resumo. Este artigo apresenta um estudo acerca do Projeto Navegapará, particularmente nos seus componentes educacionais, analisando infocentros nas escolas do município de Belém. Para tanto, foram selecionadas 26 escolas do município, nas quais foram realizadas entrevistas semiabertas com professores de laboratório, professores de disciplinas e diretores das escolas. Foi aplicado também um questionário para melhor caracterizar a amostra de escolas visitadas. Como conclusão, é feita uma breve análise dos dados obtidos e observa-se o potencial do programa e alguns pontos que precisam ser revistos, tais como proporcionar boa formação aos professores, e garantir equipamentos em bom estado de manutenção, dentre outros pontos, fundamentais para que haja um bom desenvolvimento da inclusão digital e da informática educativa dentro da escola.
\end{abstract}

Palavras-chave: inclusão digital, informática educativa, TIC e educação

\section{Analysis Of The Program For Digital Inclusion Navegapará In State Schools The City Of Belém}

\begin{abstract}
This paper presents a study concerning the Navegapará Project, particularly in its educational components, analyzing infocenters in schools in the City of Belém. To this end, 26 schools in the city have been selected, in which semi-open interviews with teachers working in laboratories, subject teachers and school principals were conducted. A questionnaire was also used to better characterize the sample of schools visited. In conclusion, we make a brief analysis of the data obtained and it is observed the potential of the program and some points that need to be reviewed, such as providing good training to teachers, and to ensure equipment in correct state of maintenance, among other things, essential to ensure good development of digital inclusion and educational computing within the school.
\end{abstract}

Key-words: digital inclusion, educational computing, TIC and education

\section{Introdução}

Os recursos e ferramentas que o computador oferece são inúmeros, graças a programas de simulação e de representação gráfica, ao armazenamento de grandes volumes de informações e sua recuperação em tempo hábil. A possibilidade de cálculos matemáticos complexos em tempo inferior aos modos convencionais, de jogos e ferramentas para suporte ao ensino/aprendizagem dentre outros, aliados às possibilidades de comunicação abertas pela rede mundial de 
computadores, constituem um rico repertório de uso educacional.

Quanto à inclusão digital, seu conceito é amplo, não significando somente o acesso ao computador e à Internet, mas também promover, por meio das novas tecnologias da informação e comunicação, a melhoria da qualidade de vida da população, haja vista que o mundo produz tanta informação que a sobrevivência solitária é cada vez mais improvável (Projeto Navegapará, 2009).

$\mathrm{Na}$ região Norte, o Governo Estadual do Pará colocou em execução o projeto Navegapará desde 2007, que visa interligar o estado via rede de fibra ótica e tecnologias complementares, com potenciais benefícios em diversas áreas, como saúde, segurança, telenegócios, governo eletrônico, educação, dentre outras (GOVERNO DO PARÁ, 2010). Essa política se materializa a partir de ações básicas como construções de infocentros públicos, infovias, rádios comunitárias e cidades digitais.

$\mathrm{Na}$ área da educação estão incluídas ações visando ao atendimento de acesso à Internet nas escolas da rede estadual, e construção de infocentros voltados à inclusão digital. Nesses infocentros, há tanto a oferta de cursos básicos de microinformática, como possibilidade de acesso à Internet.

Este artigo visa investigar de que forma o projeto está cumprindo os seus objetivos no campo educacional, especialmente o de contribuir com a qualidade da educação básica para que alunos de escolas públicas utilizem novas metodologias de aprendizagem e acessem um maior volume de conteúdos curriculares e extracurriculares, proporcionando possíveis melhorias no nível educacional e cultural.

Esta investigação será feita por meio de uma amostra representativa de infocentros já em atividade, vinculados às escolas e infocentros educacionais. Tal amostra foi formada pela escolha de escolas com maior número de alunos, afim de maior alcance populacional de envolvidos no programa.

Este artigo está dividido em cinco seções além da introdução: a seção 2 expõe o projeto Navegapará com ênfase no subprojeto Navegapará na educação; a seção 3 descreve a metodologia utilizada na coleta dos dados; a seção 4 apresenta a análise dos infocentros na educação; e, por fim, são feitas as considerações finais do trabalho.

\section{O Navegapará}

O Navegapará é um programa do Governo do Estado do Pará, lançado em março de 2007 e tem como objetivo interligar, por meio da Internet, os principais órgãos administrativos do Estado. O projeto é proveniente de convênio com a Eletronorte e a Metrobel $^{1}$. Saúde, segurança pública e educação são áreas beneficiadas por este convênio implantado de forma conjunta pela Secretaria de Desenvolvimento Ciência e Tecnologia (SEDECT) e a Empresa de Processamento de Dados do Estado do Pará (PRODEPA).

Os primeiros setores beneficiados foram os órgão públicos. Com a ação da Metrobel foi montada uma rede de fibra ótica envolvendo instituições públicas e privadas, interligando em torno de 300 unidades administrativas, como secretarias, delegacias, hospitais e escolas. Trata-se de cerca de 1.800 quilômetros de rede de fibra ótica para interligar as cidades por meio da Internet de alta velocidade às unidades administrativas. A integração do Estado será feita a partir da interligação dessas infovias com os infocentros por uma rede macro de transmissão (Wireless,2012).

Outro conceito, as "cidades digitais" representam as pequenas redes locais para onde é necessário que se baixe o sinal da Eletronorte, interligando assim um total de 61 municípios (de um total, no Estado de 143), com 300 telecentros. A primeira fase foi concluída em 2009, sendo beneficiados 15 municípios. Na segunda fase, iniciada do final de 2011, mais de 40 municípios 
foram atingidos.

\subsection{Objetivos do Projeto para a Educação}

Segundo o projeto do Navegapará (Navegapará, 2010), dentre os benefícios esperados para a área educativa estão a inclusão digital e social, a educação a distância, a formação a distância dos profissionais de educação, a modernização da gestão educacional e a videoconferência.

A responsável por formação e apoio técnico às escolas beneficiadas com o acesso é a Secretária de Educação do Estado (SEDUC). O Projeto visa contribuir com a qualidade da educação básica de forma que alunos e docentes de escolas públicas utilizem novas metodologias de aprendizagem e acessem um maior volume de conteúdos curriculares e extracurriculares. (Navegapará. 2010).

Cabe ressaltar que uma premissa importante é a adoção de procedimentos pedagógicos adequados, pois a utilização de computadores e da rede de comunicação pode representar tanto um fator positivo no processo de aprendizagem escolar como também uma barreira, na forma de dispersão, por exemplo.

\section{Metodologia}

Foi escolhido como ferramenta de coleta de dados o questionário pelo fato da amostra de escolas ser extensa, viabilizando-se assim, a análise de uma ampla quantidade de dados. O questionário empregado teve como base o instrumento elaborado por Nascimento e Mendes (2007), que é dividido em seções, que buscam conhecer o perfil e a rotina da escola antes e depois da implementação do programa. Foram realizadas, também, complementarmente, entrevistas semiestruturadas, por conterem perguntas fechadas e abertas, e desta forma possibilitarem que o entrevistado discorresse sobre o tema proposto, sem condições predeterminadas.

A pesquisa completa resultou na dissertação de mestrado "Análise do programa de inclusão digital Navegapará em escolas da rede estadual do município de Belém” (Magalhães 2012), defendida em outubro de 2012.

\subsection{A coleta de dados}

A coleta dos dados aconteceu entre outubro de 2011 e abril de 2012. Em um primeiro momento foram aplicados os questionários aos responsáveis pelo laboratório de informática das escolas e em seguida procurou-se realizar as entrevistas com esses mesmos docentes, e, conforme a necessidade, também com diretores das instituição de ensino.

Após uma primeira análise dos dados coletados, sentiu-se a necessidade de retornar em algumas escolas, para outras entrevistas, agora com docentes de disciplinas curriculares, para que estes pudessem relatar suas experiências e avaliações acerca do uso da informática educativa em suas disciplinas.

Para proceder a caracterização da amostra, foi efetuado um levantamento prévio do número de escolas estaduais no município de Belém e destas, quantas possuem um laboratório do Navegapará, sendo encontradas 244 escolas. Foi utilizado como forma de subdividir essas escolas o mesmo método empregado pela Secretaria Municipal de Educação que dividem, em Unidade Regional de Ensino (URE). A seleção da amostra dessa pesquisa utilizou $10 \%$ de cada URE, ou seja, duas escolas de cada região, o que totalizou 26 escolas. Vale ressaltar que as 26 escolas funcionam nos três turnos (manhã, tarde e noite), oito de grande porte, 14 de médio porte, e quatro de pequeno porte.

Foi escolhida a cidade de Belém devido o número populacional de alunos nesta cidade ser 
alto, além de também ter o objetivo de conhecer como é feito o projeto na capital do Estado.

O Quadro 1 mostra a quantidade de escolas selecionadas por unidades e total de alunos que cada unidade amostra possui.

Quadro 1 - Total de escolas estaduais em Belém e total de escolas selecionadas.

\begin{tabular}{|c|c|c|c|c|}
\hline UREs- Belém & $\begin{array}{c}\text { Total } \\
\text { de Escolas }\end{array}$ & $\begin{array}{c}\text { Total de } \\
\text { matrículas }\end{array}$ & $\begin{array}{c}\text { Escolas } \\
\text { Selecionadas }\end{array}$ & $\begin{array}{c}\text { Total de alunos das } \\
\text { escolas selecionadas }\end{array}$ \\
\hline Unidade 1 & 19 & 16525 & $\mathrm{~A} \mathrm{e} \mathrm{B}$ & 3.613 \\
\hline Unidade 2 & 22 & 18374 & $\mathrm{C} \mathrm{e} \mathrm{D}$ & 4.074 \\
\hline Unidade 3 & 21 & 15942 & $\mathrm{E} \mathrm{e} \mathrm{F}$ & 2.911 \\
\hline Unidade 4 & 21 & 13364 & $\mathrm{G} \mathrm{e} \mathrm{H}$ & 2.498 \\
\hline Unidade 5 & 18 & 15380 & $\mathrm{I} \mathrm{e} \mathrm{J}$ & 3.490 \\
\hline Unidade 6 & 12 & 10366 & $\mathrm{~K} \mathrm{e} \mathrm{L}$ & 3.485 \\
\hline Unidade 7 & 15 & 12381 & $\mathrm{M} \mathrm{e} \mathrm{N}$ & 4.395 \\
\hline Unidade 8 & 18 & 14119 & $\mathrm{O}$ e P & 3.181 \\
\hline Unidade 9 & 18 & 20556 & $\mathrm{Q} \mathrm{e} \mathrm{R}$ & 5.232 \\
\hline Unidade 10 & 25 & 18275 & $\mathrm{~S} \mathrm{e} \mathrm{T}$ & 4.139 \\
\hline Unidade 11 & 21 & 19517 & $\mathrm{U} \mathrm{e} \mathrm{V}$ & 4.439 \\
\hline Unidade12 & 17 & 12066 & $\mathrm{X} \mathrm{e} \mathrm{Z}$ & 3.893 \\
\hline Unidade 13 & 17 & 14439 & $\mathrm{~W} \mathrm{e} \mathrm{Y}$ & 4.136 \\
\hline TOTAL & $\mathbf{2 4 4}$ & 201304 & 26 escolas & 49.486 \\
\hline
\end{tabular}

Fonte:Quadro elaborado com base nos dados coletados na pesquisa.

Para a aplicação das novas entrevistas, foram então selecionadas seis escolas que relataram algum tipo de trabalho pedagógico com as tecnologias de informação e comunicação (TICs). As escolas foram: URE 2: escola C; URE 6: escola L; URE 8: escola O; URE 10: escola S e URE 13: Escola Y.

\section{Apresentação Dos Resultados}

Os resultados são apresentados de acordo com as seções do questionário: Perfil da escola; Perfil do responsável pelo laboratório de informática; O laboratório de informática; $O$ uso do laboratório de informática; Informática educativa na escola e Navegapará na escola.

\subsection{Perfil do Responsável Pelo Laboratório}

Todos os docentes responsáveis pelo laboratório são funcionários da escola. $84 \%$ dos docentes lotados no laboratório de informática já possuíam outro vínculo com a escola, como docente de matérias regulares em turnos diferentes, e apenas $16 \%$ dos respondentes se dedicam exclusivamente ao laboratório de informática.

Com relação à formação/capacitação dos docentes responsáveis pelo laboratório, verificou-se que todos possuem curso superior, com especialização em informática já concluída ou em andamento. Este é um ponto positivo, pois, segundo Borges (1999), o computador é explorado pelo docente especialista em sua potencialidade e capacidade, tornando possível 
simular, praticar ou vivenciar situações diferenciadas, estabelecer um modelos de conhecimento, etc. Tabela1

Quanto ao tempo de experiência, podemos observar os dados colhidos por meio da

Tabela 1 - Tempo de experiência dos docentes de laboratório

\begin{tabular}{c|c|c}
\hline $\begin{array}{c}\text { Tempo de } \\
\text { experiência }\end{array}$ & $\begin{array}{c}\mathbf{N}^{\mathbf{0}} \text { de } \\
\text { respondentes }\end{array}$ & $\mathbf{\%}$ \\
\hline Menos de 1 ano & 10 & 39 \\
\hline Entre 1 e 3 anos & 12 & 46 \\
\hline Entre 4 e 7 anos & 4 & 15 \\
\hline Mais de 7 anos & 0 & 0 \\
\hline Total & $\mathbf{2 6}$ & $\mathbf{1 0 0}$ \\
\hline
\end{tabular}

Fonte: Tabela elaborada com base nos dados coletados na pesquisa.

Constatou-se que há um número significativo de docentes que não frequentavam o treinamento oferecido pela Secretaria de Educação do Estado (SEDUC) e realizado todas as primeiras sextas feiras do mês. Quando questionado o motivo pelo qual não frequentavam o treinamento, $15(58 \%)$ justificaram a falta de tempo disponível, pois, apesar de ser realizado apenas uma vez ao mês, é difícil deixar de ir à escola para fazê-lo. Ainda, segundo estes 15 respondentes, com a ausência deles na escola, o laboratório não funcionaria. Os seis (23\%) respondentes restantes admitiram que não frequentam o treinamento por comodidade.

São números preocupantes, pois embora seja apenas uma capacitação mensal, há motivos que levam o docente à perda deste momento, motivos já conhecidos e rotineiros: sobrecarga de atividades na escola, necessidade de dar aulas em mais escolas, em até três turnos.

\subsection{O laboratório de informática}

Em todas as 26 escolas foi confirmado que já existia um lugar destinado ao laboratório de informática, porém, antes da implementação do programa, em $92 \%$ destas, o espaço não comportava o número de alunos de uma mesma turma. No período em que foi realizada a pesquisa, já com a implementação do Navegapará, apenas 31\% dos laboratórios comportavam uma turma inteira; $69 \%$ destes ainda precisavam sofrer adequações.

Quanto à quantidade de computadores destinados ao uso pedagógico, verificou-se que em $42 \%$ das escolas há entre dez e 15 computadores e em 58\% há mais de 15 computadores. Cabe ressaltar que estes dados refletem apenas o número de computadores que estão em boas condições de uso. Para todos os respondentes o número de máquinas ainda é insuficiente, o que pode ser ilustrado pelo relato de uma docente do laboratório de informática de uma das escolas pesquisadas, em que apenas 11 das 20 máquinas estão em condições de uso.

Estas máquinas estão paradas há meses, e os problemas de cada uma são simples. São apenas o mouse que não está funcionando, o teclado que está com algumas teclas quebradas, dentre outras coisas "bobas", que apesar de fáceis de se resolver, eu não tenho como fazer isto. $\mathrm{O}$ procedimento eu já fiz, liguei e pedi para que o técnico trouxesse o que está faltando, mas até agora nada; já se passaram três semanas, até me ofereci para ir buscar, mas não posso porque tem-se que seguir as regras deles (Relato do docente da escola H, 2012). 
O problema de máquinas paradas por falta de manutenção é recorrente. A escola não tem autonomia para agir nesses pequenos problemas do dia a dia. Para todo tipo de manutenção é necessário que haja uma solicitação, logo, com o número insuficiente de técnicos e de disponibilização de recursos, esses problemas para serem resolvidos acabam demorando semanas, e até mesmo meses, como relatou a docente da escola $\mathrm{H}$.

No que se refere à relação de alunos por máquina, no laboratório, averiguou-se que em $30 \%$ havia dois alunos por máquina, em $60 \%$ dos casos havia três alunos por máquina, e em 10\% havia mais de cinco alunos por máquina, relação certamente desfavorável ao aprendizado.

Além do número de alunos por computador, outra dificuldade reside no tamanho das turmas. Uma pesquisa educacional do Centro de Organização Social e Escolar da Johns Hopkins University, em Baltimore mostrou que turmas com média de 17 alunos tiveram melhor desempenho na utilização da informática do que as turmas que variavam de 35 a 40 alunos, que é a média das turmas nas escolas estaduais de Belém.

Com relação à utilização da internet no laboratório, apurou-se que em $69 \%$ das escolas a internet encontrava-se funcionando, mesmo que não diariamente. Este funcionamento em dias rotativos deve-se a oscilações de problemas rotineiros, como a velocidade de conexão que varia a cada dia, a falta de manutenção e/ou problemas de redes. Em 31\% das escolas não havia o serviço da internet no laboratório há semanas.

As dificuldades enfrentadas com o serviço de manutenção dos laboratórios e o que os docentes dos laboratórios fazem para continuar as atividades podem ser exemplificadas por meio do relato a seguir:

Tanto eu quanto os outros docentes dos outros turnos já ligamos para o técnico responsável pela nossa USE e até agora nada. Já estamos há cinco semanas sem Internet. Para prosseguir as aulas aqui na sala de informática e não desestimular o docente a vir pra cá com a sua turma eu faço o seguinte: converso antes com o docente da disciplina e fico a par do conteúdo da aula, vou para casa e pesquiso em casa todo o conteúdo que o docente dará na próxima aula, gravo este conteúdo no meu pendrive e trago pra cá, e antes da aula, gravo este conteúdo de máquina em máquina (Relato do docente da escola I, 2012).

A grande demanda de solicitações de manutenção acaba formando um fila de chamadas que os poucos técnicos não são capazes de atender com agilidade. No geral tem-se apenas um técnico para cada URE, ou seja, um técnico para atender cerca de 18 escolas.

\subsection{Uso do laboratório de informática}

Com relação à frequência com que o aluno utiliza o laboratório de informática, as respostas revelaram que $46 \%$ dos alunos só o utilizam quando o docente da sala de aula sente a necessidade de levar a turma para este espaço. Em 23\% dos casos, os alunos vão ao laboratório quando sentem necessidade, sem que haja necessariamente um pedido do docente e $31 \%$ o frequentam mais de uma vez por semana. Essa frequência na sala de informática se deve a aulas e também a necessidade de pesquisas, digitação de trabalho, dentre outros.

Questionou-se, também, sobre quais outras atividades, que não sejam aulas, são realizadas no laboratório. Em todas as escolas pesquisadas, trata-se de atividades como a digitação de trabalhos, a navegação na Internet e as pesquisas acadêmicas. Em oito (31\%) das 26 escolas também são realizadas atividades voltadas à comunidade, tal qual a formação e capacitação de jovens e adultos para o uso do computador. Essas atividades são realizadas por centros comunitários, em que a monitoria e as atividades ficam a cargo de uma pessoa da comunidade, ligada à escola. 
Sobre a utilização do laboratório como ferramenta de uso pedagógico, constatou-se que em $42 \%$ das escolas analisadas somente os responsáveis pelos laboratórios faziam seu uso com esta finalidade, embora a ampliação deste uso possa ser bem interessante, especialmente de forma lúdica (MACEDO, PETTY e PESSOA, 2005. p.13).

Estimular os docentes a inserir os recursos que a tecnologia oferece para estimular os alunos e facilitar a aprendizagem é um dos pontos iniciais e primordiais da informática na educação. Porém, atrair os docentes não é uma tarefa fácil. Note-se o relato do docente de informática da escola S.

Nós tentamos atrair os docentes para o ambiente do laboratório de informática, mas não há nenhum incentivo além do nosso. Eu conheço os recursos que a informática oferece e os benefícios que nós docentes podemos obter através da utilização desta na nossa forma de lecionar, sei disso porque fiz especialização em TI, mas os outros docentes não sabem. Não há uma capacitação decente, um material informativo ou algo que a SEDUC faça para que os outros colegas conheçam o arsenal que temos aqui, na nossa escola e que não é tão aproveitado como poderia (Relato do docente da escola S, 2012).

Saviani (2000) afirma as políticas educacionais exercem papel preponderante. Neste sentido, uma política de capacitação/qualificação que fosse aplicada a esses docentes juntamente com outras políticas que garantissem bons salários, condizentes com uma carga horária de trabalho que lhes permitisse buscar se aperfeiçoar e investir na sua formação, seria o ideal para que ações voltadas à informática na educação fossem realizadas com sucesso. Assim ter-se-iam profissionais bem preparados para conduzir suas aulas e seus alunos, utilizando as tecnologias como meio de ensino-aprendizagem.

Em 61,5\% das escolas, antes da implementação do Navegapará, o laboratório de informática já era utilizado pelo responsável por esse local e por poucos docentes de disciplinas, como observado no relato a seguir:

Eu procuro incentivar os docentes a usarem o laboratório nas suas aulas, ao menos uma vez por mês. Os alunos gostam, deixa as aulas mais interessantes, com a utilização do data show, por exemplo ou a pesquisa na internet sobre o assunto da aula. É claro que há a possibilidade de dispersão, aliás o que ocorre muito, mas a gente fica de olho, tenta orientá-los...é como em casa, o pai dá o computador pro filho estudar, mas se ele não ficar de olho a criança pode não usar aquilo para os estudos e só ficar em chats, em Orkut e etc. (Relato do docente da escola A, 2012).

Para Moran (2009), as formas de comunicação online são muito apreciadas pelos alunos e bastante desvalorizadas pelos docentes. O docente alega a dispersão e o não aprofundamento das questões propostas durante as aulas como empecilhos à absorção do conteúdo. Porém, este mesmo autor ainda afirma que a predisposição dos alunos para a conversa online faz parte dos seus hábitos na internet.

\subsection{Informática educativa na escola}

Quanto aos problemas enfrentados no laboratório que prejudicam o seu uso pedagógico, estes são muito variados e nem mesmo os respondentes conseguiram citar qual seria o maior deles. A Tabela 2 revela que há problemas que costumam ocorrer com maior frequência na maioria das escolas. 
Tabela 2 - Problemas mais frequentes nas escolas

\begin{tabular}{|c|c|}
\hline Problemas & \% de respostas positivas \\
\hline Infraestrutura & $88,00 \%$ \\
\hline Ausência de manutenção no laboratório & $88,00 \%$ \\
\hline Acúmulo de trabalho dos docentes & $31,00 \%$ \\
\hline Dificuldade de conexão com a Internet & $53,00 \%$ \\
\hline $\begin{array}{c}\text { Desconhecimento do potencial da Informática educativa por parte } \\
\text { do corpo docente }\end{array}$ & $46,00 \%$ \\
\hline Pouca familiaridade com a tecnologia & $46,00 \%$ \\
\hline
\end{tabular}

Fonte: Tabela elaborada com base nos dados coletados na pesquisa

Infraestrutura e falta de manutenção dos laboratórios são os problemas que mais se repetem. Cerca de $88 \%$ das escolas sofrem com essas dificuldades. Outros problemas tais como dificuldade de conexão com a internet, pouca familiaridade com a tecnologia, desconhecimento do potencial do uso da informática na educação por parte do corpo docente e dificuldade em encontrar tempo para se dedicar a trabalhar com a tecnologia devido ao acúmulo de atividades também foram apontados pelos respondentes.

Na escola I da URE 5, foi encontrado o pior estado dentre as 26 escolas. O laboratório de informática não possuía nenhum computador com conexão à internet havia quase três semanas, as bancadas estavam organizadas viradas de costas para o docente e para a parede onde era projetada a videoaula. Dos 18 computadores que o laboratório possuía, apenas dez estavam em condições de uso e o refrigerador de ar estava com defeito. Segundo a diretora da escola, o problema das bancadas não tinha como ser resolvido, pois estas eram fixas não podendo ser modificado o posicionamento sem que fossem trocadas.

Em 31\% das escolas não existia nenhum projeto relacionado à informática educativa com os alunos, antes do Navegapará, enquanto $69 \%$ das escolas já desenvolviam algum projeto de informática educativa. $\mathrm{O}$ relato da docente da escola $\mathrm{O}$ retrata esta situação.

Nós procurávamos introduzir a informática no cotidiano dos alunos. Eles já eram trazidos para cá pelo menos uma vez ao mês para recreação e duas vezes ao mês para atividades complementares da sala de aula. Com isso os alunos frequentavam a sala quase que toda semana. As atividades complementares eram feitas em parceria entre alguns docentes, como por exemplo o docente de língua estrangeira, que passava uma música e os alunos acompanhando pela letra, procuravam a fonética correta das palavras. O docente de biologia que utilizava imagens da Internet para exemplificar suas aulas (Relato do docente da escola A, 2012).

Ao analisar o relato deste docente, reflete-se sobre o papel do docente que pode deixar de seguir radicalmente a abordagem tradicional de ensino e reconhecer que este pode ser feito por meio de novas metodologias, nas quais ele continua sendo o transmissor/mediador do conhecimento, porém, agora o aluno ganha mais autonomia e passa ter um papel mais ativo nesse processo. Para Saviani (2000), deve-se sempre frisar que esta autonomia do aluno deve ser acompanhada de conteúdos estabelecidos, haja vista que ensino não pode ser identificado diretamente com a pesquisa.

Foi também perguntado como se deu o processo de implementação do Navegapará nas escolas. Dos 26 respondentes, apenas nove (34\%) participaram da implementação, pois já trabalhavam há mais de um ano na escola. Os outros 17 (65\%) respondentes tiveram que solicitar a ajuda de funcionários mais antigos para responder a esta pergunta. $O$ processo de implementação nas 26 escolas foi semelhante. Na maioria dos casos (19 escolas, ou seja, 73\%), primeiro chegaram as máquinas, que ficaram paradas, esperando a instalação e a reforma da sala 
de informática, para que, enfim, pudessem ser instaladas. Essa espera, em todas as 19 escolas foi de mais de oito meses. Apenas em sete $(27 \%)$ escolas, as máquinas foram instaladas no mesmo bimestre em que chegaram.

Torres (2002) afirma que introduzir de forma eficaz as TICs na escola implica não só provisão massiva de computadores e acesso à Internet mas também ao reordenamento da infraestrutura, da administração, do currículo, da pedagogia e da formação dos docentes como usuários competentes das chamadas TICs, tanto para o ensino como para sua própria aprendizagem permanente.

Para que o uso das TICs na prática do ensino-apredizagem tenham um ganho significativo, é necessário que a escola que busca o uso das TICs como ferramentas nas sala de aulas, passe por uma transformação e que seja receptiva as mudanças e a novos modelos metodológicos, se for necessário, readequando o currículo e requestionando qual o significado da aprendizagem.

Porém é necessário compreender como cada sujeito dentro da escola reage à introdução das TICs na escola. Com isso buscou-se verificar como cada ator recebeu o programa. Sobre a aceitação do Navegapará na instituição tem-se o Quadro2.

Quadro 2 - Aceitação dos sujeitos das escolas ao Navegapará

\begin{tabular}{|c|c|c|c|c|}
\hline Sujeitos & Ausente & Pequena & Média & Grande \\
\hline Alunos & 0 & 0 & 2 & 11 \\
\hline Docentes & 0 & 19 & 7 & 0 \\
\hline $\begin{array}{c}\text { Técnicos } \\
\text { Administrativos }\end{array}$ & 0 & 0 & 7 & 12 \\
\hline Coordenação e direção & 0 & 0 & 15 & 6 \\
\hline
\end{tabular}

Fonte: Quadro elaborado com base nos dados coletados na pesquisa

Pode-se observar que a aceitação dos alunos, dos técnicos, da coordenação e direção das escolas, em geral, foi de média a grande. Isso deve ser motivado pela expectativa do novo que vem com a proposta de facilitar os interesses de cada grupo. Já a aceitação dos docentes foi razoável. Isso reflete uma certa resistência em aceitar a introdução de mudanças que podem vir a alterar a rotina e as tarefas já praticadas.

Ao se averiguar os motivos pelos quais os docentes não utilizavam o laboratório com mais frequência, $45 \%$ dos respondentes afirmaram ser devido à insegurança que estes sentem para trabalhar com a informática e $55 \%$ responderam que o motivo é a falta de tempo na carga horária dos docentes. Segundo estes docentes, esta insegurança do docente vem da falta de preparo deste para realizar aulas nos laboratórios de informática. Esta falta de preparo é devida a falta de conhecimentos na utilização de um software e do funcionamento dos equipamentos que acaba fazendo com que este profissional evite aulas no laboratório.

Constatou-se, em campo, com esta pesquisa, que o treinamento, ou "capacitação" muitas vezes ocorre de modo informal, no qual os docentes dos laboratórios dividem seus conhecimentos com os colegas de disciplinas regulares durante os intervalos de turnos.

Nenhuma das escolas visitadas usam softwares educativos específicos para auxiliar no processo de aprendizagem. O que foi levantado é que em $69 \%$ destas, os docentes usam jogos do próprio Linux que são educativos. Alguns alunos usam tutoriais pesquisados na internet e alguns docentes usam exercícios online, mas isso esporadicamente.

\section{Conclusão}

É importante o desenvolvimento de políticas públicas que invistam na popularização das TICs como uma forma de facilitar a vida da população, possibilitando encurtar distâncias, 
melhorar atendimentos médicos, reforçar a segurança, agilizar atendimentos e diminuir a espera em órgão públicos, além de tornar mais fácil a comunicação entre macro e microrregiões.

Dessa forma, o Navegapará vem com uma política pública de inclusão digital que visa trazer benefício à educação pública do estado, como a possibilidade de inserção da informática educativa na formação dos alunos. Para verificar como este programa vem beneficiando a educação, foi analisada nesta pesquisa uma amostra de 26 escolas do município de Belém, em que foram aplicados dois instrumentos de coleta de dados: questionário e entrevistas.

Os resultados obtidos foram importantes no sentido de indicar a necessidade de melhoramento do programa em diversos aspectos, principalmente no que diz respeito à manutenção e ao trabalho realizado na escola depois da instalação dos laboratórios. Vale a pena ressaltar que, para um projeto de inclusão digital obter sucesso e garantia de que seus objetivos sejam alcançados, não basta disponibilizar equipamentos e infraestrutura. É necessário que haja um amplo projeto coeso, que inclua acompanhamento, avaliação e manutenção.

É importante ressaltar que desde a análise do projeto verificou-se que não há nenhum objetivo específico que comporte de fato a inclusão digital na educação. O projeto do programa Navegapará trata da educação de forma abrangente em seu documento, o que já permite se questionar acerca da prioridade do setor educacional e da viabilidade em assegurar medidas eficazes para a inserção das tecnologias de informação e comunicação na educação.

Conclui-se contudo que, para utilizar as TICs na educação deve-se zelar não somente por tornar a tecnologia materialmente acessível. Percebe-se que este é um grande desafio não somente (porém principalmente) para o governo, mas também, para os docentes, diretores e toda comunidade escolar.

\section{Referencias}

AGÊNCIA PARÁ. dispõe de informações sobre a implementação do Navegapará. Disponível em: http://www.agenciapara.com.br/exibe_...p?id_ver=52440. Acessada em 20 de outubro de 2012.

AMSTRONG, A.; CASEMENT, C. A Criança e a Máquina: como os computadores colocam a educação de nossos filhos em risco. Trad. Ronaldo Cataldo Costa. Porto Alegre: ArtMed, 2001 .

BORGES NETO, H. Uma classificação sobre a utilização do computador pela escola. Revista Educação em Debate, Fortaleza. 1999.

DANTAS, A. S. Holanda, M. J. V. A importância do profissional responsável pelo laboratório de informática para a inclusão digital da comunidade escolar: A experiência da escola municipal Senador Duarte Filho.2008.

FERREIRA, B P. Experiências de informática Educativa no Município de Belém: Um Quadro Inicial de Diagnóstico. In: XII WIE, XXVI Congresso da SBC, Campo Grande/MS, 14 a 20 de julho, pp. 182-188, 2006.

FREIRE, P. Educação como prática da liberdade. 6 ed. Rio de Janeiro: Paz e Terra,1976.

GOVERNO DO PARÁ. Projeto de Implementação Navegapará. 2010

GOVERNO DO PARÁ. Guia para Inclusão Digital do Navegapará. Manual do cidadão. 2009

GUIA DAS CIDADES DIGITAIS. Navegapará entra na segunda fase. Disponível em: $<$ http://www.guiadascidadesdigitais.com.br/site/pagina/navegapar-entra-na-segundafase > 
Acessado em: 30 de outubro de 2013.

MACEDO, L; PETTY, A.L. S; PASSOS, N. C. Os Jogos e o Lúdico na aprendizagem escolar. Artmed, Porto Alegre. 2005.

MAGAlHÃES, W. M. Análise do Programa de Inclusão Digital Navegapará em Escolas da Rede Estadual do Município de Belém. UFPA, 2012.

MORAN, J. M. A educação que desejamos: Novos desafios e como chegar lá. $4^{\mathrm{a}}$ ed, Papirus, 2009.

NASCIMENTO, M. P. S. ; MENDES, T. C. Informática educativa em escolas de $\mathbf{1}^{\mathbf{a}}$ a $\mathbf{4}^{\mathrm{a}}$ séries no município de Belém. Trabalho de Conclusão de Curso, UFPA, Curso de Bacharelado em Sistemas de Informação, 2007.

SAVIANI, D. Escola e Democracia: teorias da educação, curvatura da vara, onze teses sobre educação e política. 33. a ed. revisada. Campinas: Autores Associados, 2000.

SECRETARIA DE EDUCAÇÃO DO ESTADO DO PARÁ. SEDUC. Disponível em www.seduc.pa.gov.br/ . Acessado em 21 de outubro de 2013.

TORRES, R. M. Educação para Todos. Porto Alegre: Editora Artmed, 2002.

- Índice Brasil de Cidades Digitais. Wireless 2012. Disponível em http://www.wirelessmundi.inf.br/edicao-n-9/931-as-100-cidades-do-ibcd-2012-regiao-norte . Acesso em 09 Julho 2013. 